\title{
Homogenous Mothers-in-law, Different Daughters-in-law: In-law Relationship Comparison between Vietnamese and Taiwanese Daughters-in-law
}

\author{
Li-Ching $\operatorname{Sun}^{1} \&$ Yi-Fang Lin $^{2}$ \\ ${ }^{1}$ Department of Early Childhood Education, National Chia-Yi University, Chia-Yi, Taiwan \\ ${ }^{2}$ Hi-Pu Elementary School, Changhua, Taiwan \\ Correspondence: Li-Ching Sun, Department of Early Childhood Education, National Chia-Yi University, \\ Chia-Yi, Taiwan. Tel: 011-88-69-2028-8231. E-mail: sunlc@mail.ncyu.edu.tw
}

\author{
Received: October 14, 2014 Accepted: November 26, $2014 \quad$ Online Published: January 14, 2015 \\ doi:10.5539/ass.v11n4p252 URL: http://dx.doi.org/10.5539/ass.v11n4p252
}

\begin{abstract}
The purpose of this study is to compare the mother-/daughter-in-law relationship of Taiwanese daughters-in-law and Vietnamese daughters-in-law. For this research, 266 Vietnamese and 509 Taiwanese daughters-in-law were selected as the subjects. The results indicated that, when compared with their Taiwanese counterparts, Vietnamese daughters-in-law felt they had a significantly more positive relationship, due to the support and companionship of their mothers-in-law. On the other hand, Vietnamese daughters-in-law also recognized that their mothers-in-law had a more dominant role. In addition, daughters-in-law of families with a household income less than NTD 30,000 (around USD 1,000) and an educational level of middle school or less felt that their mothers-in-law were more dominate. The findings also showed that mothers-/daughters-in-law who never lived together had a less positive or negative relationship. However, contrary to expectations, when excluding factors such as the educational level of the daughter-in-law, family income and proximity valuables, the ethnicity of the daughter-in-law still made a significant difference in the support, companionship, and dominance of the relationship.
\end{abstract}

Keywords: foreign daughter-in-law, in-law relationship, intergenerational relations

\section{Introduction}

In a Taiwanese family, the relationship between the daughter-in-law and mother-in-law is very complicated and difficult to deal with (Hsu \& Huang, 2006). Traditionally, once a woman is married, she must live with her husband's family. The daughters-in-law have the lowest ranking in the husband's family, so they must obey, take care of, and show filial piety towards their mothers-in-law. Nowadays, thanks in part to big changes in Taiwanese society, women receive a better education and have daughter-in-law status which is higher than in the past, especially for the more highly educated women. However, cultural norms such as filial piety and respect for elders are still in place, hence the daughter-in-law is still expected to follow these norms and respect her mother-in-law (Kung, 1999). As a mark of respect and filial piety, the daughter-in-law should not question the mother-in-law's decisions.

During the last decade, about two hundred thousand foreign women have married into Taiwanese families. The majority of the women come from poverty-stricken areas in Southeast Asia (Ministry of the Interior, 2011). Most of them met their husbands through a transnational marriage agency system. Although these couples meet several times before their marriage, they do not know each other very well. According to past research, the men who go through this process are often from Taiwan's lower class (U. Wang, 2005). For these males, their main reason for marriage is to pass down the family name, and have someone take care of their elders as well as maintain their households. For the women, it is to financially support and improve the quality of life for her original family in Vietnam. The couples live with the husbands' parents after marrying and the women become pregnant soon after.

According to population statistics from the Ministry of the Interior (2011), the largest segment of women who go through with the transnational marriages are from Vietnam. There, women are supposed to take on the responsibility of maintaining the household, be loyal to the husband and be diligent. These are the qualities 
traditional Taiwanese men prefer and that is the reason why most of these women are from Vietnam.

In a Taiwanese-Vietnamese marriage, the relationship between a daughter-in-law and her mother-in-law has several characteristics: (1) it would appear that they get along very well, harmoniously working together. However, there is unnoticeable tension building in this relationship due to differences in language, cultural beliefs, and customs (Wang, 2007). (2) The daughters-in-law prefer to go out and find employment, then send money back to their homeland, giving financial support to their Vietnamese families. However, the mothers-in-law often forbid the daughters-in-law from employment and prefer that they focus on taking care of the household (Wang, 2007). (3) The mothers-in-law have a strong preference for male offspring, which places a lot of pressure on the daughters-in-law. Once a child is born, the mother-in-law is the main caregiver (Wang, 2007). (4) A mother-in-law has the power to make decisions to which the daughter-in-law usually submits (Su, 2007).

Shen (2003) found that, although Vietnamese daughters-in-law recognized their expected role as the daughter-in-law, they would not accept the rules of this role entirely. Compared with Taiwanese daughters-in-laws, they lack the support of social network, but at the same time, there are no moral restraints from social network. Do Vietnamese and Taiwanese daughters-in-law follow the same rules of the mother-/daughter-in-law relationship? When faced with a mother-in-law from a different cultural background, nationality, and language, how do Vietnamese daughters-in-laws deal with their mothers-in-law? With the changing times in Taiwan, women have the same education opportunities as men and there are more and more career women. Furthermore, the status and norms of the daughter-in-law in a family are also transforming ( $\mathrm{Su}$, 2007). In the shifting mother-/daughter-in-law relationship, will there be any difference due to the family income, educational level or career of the daughter-in-law? These are the issues that this study shall attempt to explore.

\section{Literature Review}

A review of the literature focuses on the potential influential factors in the mother-/daughter-in-law relationship. Such factors include living proximity between the mother-in-law and daughter-in-law, educational level of the daughter-in-law, family income as well as the cultural factor mentioned above.

\subsection{Living Proximity between the Mother-in-law and Daughter-in-law}

From the viewpoint of western society, the mother-in-law is the most difficult in-law (Duvall, 1954). Because the mother-in-law and daughter-in-law shared with the same man, competitive mentality may exist between these two women. The mother-in-law may sense that her importance to her son will be taken over by the daughter-in-law, while the daughter-in-law may feel that the mother-in-law is interrupting her own family. According to Duvall's (1954) model, good in-law relationships are based on the complete autonomy of young couples. Young couples are not completely independent of the older generation if they live together or nearby. Because family members have different values and needs, close proximity may arise conflict and stress. However, a study by Marotz-Baden and Cowan (2009) found that there are no significant correlations between proximity and stress in Montana farm and ranch families. Similar findings showed that in Taiwanese dual-earner families, proximity is not a significant factor (Tsai \& Chen, 2004). Oppositely, daughters-in-law hold positive perception toward their mothers-in-law when they live together (Tsai \& Chen, 2004). According to qualitative studies, when mothers-/daughters-in-law live together, assistance from the mother-in-law is a wonderful family resource, although differences in lifestyle habits and unequal household authority can cause many conflicts between the mother-/daughter-in-law (Kung, 1999; Hsu \& Cheng, 2006).

\subsection{Educational Level of the Daughter-in-law}

In Taiwan, improvement of the relative position of the daughter-in-law to her mother-in-law can be contributed to education. In general, more educated women are apt to marry at a later age and tend to be more independent than women with less formal schooling (Willams, Mehta, \& Lin, 1999). However, under the protective umbrella of filial piety and respect for elders, the mother-in-law still have higher family ranking and more authority (Kung ,1999). A research conducted by Chen (2006) with 1,257 Taiwanese mothers investigated the educational level association with traditional social role norms such as obedience to authority, filial piety, respect of ancestors, discipline and restraint. Subjects with college degree or higher were found to be significantly less associated with the role norms than those with high school diploma or less. Additionally, when regression analysis was performed using role norm as the independent variable and harmonious mother-/daughter-in-law relationship as the dependent variable, Chen (2006) found that the more identification with these role norms the subjects had, the more harmonious their mother-/daughter-in-law relation were. In other words, the mother-/daughter-in-law relationships of daughters-in-law with a higher educational level were less harmonious than those with a lower educational level. 


\subsection{Financial Situation}

Studies on Taiwanese mother-/daughter-in-law relationships seldom mention money, only a subject in an interview by Kung (1999) remarked that a mother-in-law would not be pleased if her daughter-in-law spent money earned by her son. On the other hand, family economic issue has been mentioned in every article regarding families with Vietnamese daughters-in-law. The usage of money could spark a conflict between mother and daughter in-law. For instance, there would be quarrels regarding the Vietnamese daughter-in-law sending money to Vietnam or visiting her original family in Vietnam, telephone calls, taking the taxi, or other spending that the mother-in-law disagrees with (Wang, 2007). The Taiwanese mother-in-law worry that the Vietnamese daughter-in-law would take the son's hard earned money and flee back to Vietnam, never to return again; whereas most Vietnamese daughters-in-law come from poverty-stricken areas and hope to financially improve the quality of life for their original families by way of their marriage. Hence, the two sides differ on use of money and ill feelings arise ( $\mathrm{Su}, 2007)$.

The present study covers three broad purposes: (1) to determine whether mother-/daughter-in-law relationship differences exists between Vietnamese and Taiwanese daughters-in-laws; (2) to assess whether mother-/daughter-in-law relationship differences are due to the educational level of the daughter-in-law, employment, family income, and proximity; and (3) to explore differences in the mother-/daughter-in-law relationship due to ethnicity once the mentioned other factors have been controlled.

\section{Method}

\subsection{Subjects}

The subjects consisted of 266 Vietnamese and 509 Taiwanese daughters-in-law with children who were kindergarten or first grade age. These participants were recruited through their children's schools: 26 elementary schools and 22 preschools in the southern areas of Taiwan.

\subsection{Measurements}

1) Demographic questionnaire: The subjects were asked to provide some basic background information pertaining to their own age, educational levels, employment status, and the family's monthly income.

2) Proximity: The proximity between mother-in-law and daughter-in-law was measured by a forced choice format containing questions related to their experience of living together.

3) The Mother-in-law Relationship (RML): This 20 -item scale was developed by the authors of the current study in order to assess the style of relationship with mother-in-law. Each item was rated on a 6-point Likert scale, with possible responses ranging from none to the most. Through the use of a principal component factor analysis with varimax rotation of all items, the results yielded a four-factor solution: support, companionship, conflict and dominance. Item loadings were from .55 to .97 , and these factors gave a variance total of $74.96 \%$. The Cornbach's alpha coefficients were $.91, .88, .77$ and .95 .

\section{Results}

\subsection{Demographic and Proximity Variables}

The ages of the Vietnamese daughters-in-law ranged from 20 to 50 , with an average age of 31.39 years ( $\mathrm{SD}=$ 4.26). The average age of the Taiwanese daughters-in-law was $35.39(\mathrm{SD}=4.98)$. In the level of education, $71.6 \%$ of the Vietnamese daughter-in-law had a middle school or less education. On the contrast, $91.5 \%$ of Taiwanese daughters-in-law had a high school diploma degree or higher education. 55\% of families with Vietnamese daughters-in-law and only $12.2 \%$ of families with Taiwanese daughters-in-law had a household income lower than NTD 30,000 (approximately USD \$1,000) per month (see Table 1). The frequency of proximity showed that $42 \%$ of Taiwanese daughters-in-law and $55 \%$ of Vietnamese daughters-in-law were living with their mothers-in-law.

\subsection{Difference in the Mother-/Daughter-in-law Relationship Due to Ethnicity}

A $2 \times 4$ analysis of variance with repeated measure was conducted on the ethnicity of the mother-/daughter-in-law relationship. The analysis revealed that the interaction between ethnicity and relationship was significant $(\mathrm{F} 3,765=4.57, p<.01)$. A series of post hoc t-tests were conducted. The results showed that, with support and companionship from their mothers-in-law, Vietnamese daughters-in-law had a significantly more positive relationship than the Taiwanese daughters-in-law. Even though the Vietnamese daughters-in-law had less conflict with their mothers-in-law than the Taiwanese daughters-in-law, they felt that the mother-in-law role was more dominant than Taiwanese daughters-in-law did. Table 2 shows the subjects' mean response scores and $\mathrm{T}$ values. 
Table 1. Numbers and frequency of educational level, employment status, family monthly income and proximity

\begin{tabular}{lll}
\hline & Taiwanese daughters-in-law & Vietnamese daughters-in-law \\
\hline Educational level & & \\
Middle school or below & $43(8.5 \%)$ & $189(71.6 \%)$ \\
High School & $174(34.6 \%)$ & $29(11.0 \%)$ \\
$2-3$ years college & $147(29.2 \%)$ & $38(14.4 \%)$ \\
BS and advanced & $140(27.7 \%)$ & $8(3.0 \%)$ \\
Employed & $358(70.3 \%)$ & $173(65.0 \%)$ \\
Family monthly Income & & \\
30,000 or below & $60(12.2 \%)$ & $146(55.3 \%)$ \\
$30,001-50,000$ & $151(30.4 \%)$ & $83(35.3 \%)$ \\
$50,001-70,000$ & $146(29.4 \%)$ & $20(7.5 \%)$ \\
70,000 or above & $139(30.0 \%)$ & $5(1.9 \%)$ \\
Proximity & & \\
Never lived together & $90(17.7 \%)$ & $33(12.4 \%)$ \\
Have lived together previously & $149(29.3 \%)$ & $67(25.2 \%)$ \\
Occasionally lived together & $57(11.2 \%)$ & $21(7.9 \%)$ \\
Living together & $213(41.8 \%)$ & $145(54.5 \%)$ \\
\hline
\end{tabular}

Table 2. Means, standard deviations and $\mathrm{T}$ value between Taiwanese and Vietnamese daughters-in-law in the mother-/daughter-in-law relationship

\begin{tabular}{llll}
\hline & Taiwanese daughters-in-law M (SD) & Vietnamese daughters-in-law M (SD) & T value \\
\hline Support & $3.04(1.30)$ & $3.52(1.56)$ & $-4.52^{* * *}$ \\
Companionship & $3.27(1.20)$ & $3.49(1.45)$ & $-2.21^{*}$ \\
Conflict & $2.62(1.12)$ & $2.59(1.49)$ & .348 \\
Dominance & $2.17(1.14)$ & $2.57(1.54)$ & $-4.12^{* * *}$ \\
\hline
\end{tabular}

Note. ${ }^{*} p<.05, * * p<.01, * * * p<.001$

\subsection{Difference in the Mother-/Daughter-in-law Relationship Due to Education Level, Family Income, and Proximity}

A series of one-way ANOVA was conducted to compare mother-/daughter-in-law relationship for the demographic data, especially on educational level, family income and proximity. There were two significant differences in educational level for Support relationship (F 3, $764=4.473, p=.004)$ and for Dominance (F 3, $764=4.181, \mathrm{p}=.006$ ). The further analysis used Scheffe multiple comparison and the results indicated that daughters-in-law with middle school diploma or less $(\mathrm{M}=3.44, \mathrm{SD}=1.51)$ felt they had more support from mothers-in-law than did daughters-in-law with high school diploma $(\mathrm{M}=2.95, \mathrm{SD}=1.36)$. However, daughters-in-law who had middle school diploma or less $(\mathrm{M}=2.54, \mathrm{SD}=1.48)$ felt significantly more dominance from the mother-in-law than did daughters-in-law who had college $(\mathrm{M}=2.18, \mathrm{SD}=1.16)$ and university or higher degree $(\mathrm{M}=2.13, \mathrm{SD}=1.13)$. Family income was significant on dominance relationship (F 3, $757=3.122, \mathrm{p}=.025)$. Results of Scheffe multiple comparison test indicated that daughters-in-law whose families had a household income lower than NTD 30,000 $(\mathrm{M}=2.49, \mathrm{SD}=1.44)$ felt more dominance from the mother-in-law than did daughters-in-law whose families had a household income higher than NTD 70,000(M= $2.49, \mathrm{SD}=1.44)$. However, there was no significant difference in the mother-/daughter-in-law relationship due to employment status.

The analysis also revealed significant differences in Proximity. According to the post hoc results, daughters-in-law who lived with their mothers-in-law felt they had more support and companionship than did the daughters-in-law who had never lived, or previously lived with their mothers-in-law. On the other hand, the daughters-in-law who had never lived with their mothers-in-law felt there was less conflict and dominance than the daughters-in-law did who used to, or who are now living with their mothers-in-law. Table 3 shows the mean and standard deviations for proximity in the mother-/daughter-in-law relationship. 
Table 3. Means, standard deviations and F-value for proximity in the mother-/daughter-in-law relationship

\begin{tabular}{lllllll}
\hline & $\begin{array}{l}\text { 1.Never lived } \\
\text { together }\end{array}$ & $\begin{array}{l}\text { 2.Previously } \\
\text { lived together }\end{array}$ & $\begin{array}{l}\text { 3.Occasionally } \\
\text { lived together }\end{array}$ & $\begin{array}{l}\text { 4.Living } \\
\text { together }\end{array}$ & F & \\
\hline Support & $2.64(1.45)$ & $3.04(1.34)$ & $3.23(1.31)$ & $3.49(1.39)$ & $13.24^{* * * *}$ & $\begin{array}{l}4>2>1, \\
3>1\end{array}$ \\
Companionship & $2.78(1.35)$ & $3.20(1.24)$ & $3.40(1.23)$ & $3.61(1.26)$ & $14.68^{* * * *}$ & $\begin{array}{l}4>2>1, \\
3>1\end{array}$ \\
Conflict & $2.10(1.05)$ & $2.63(1.25)$ & $2.64(1.27)$ & $2.77(1.29)$ & $9.09^{* * *}$ & $\begin{array}{l}2, \\
4>1,\end{array}$ \\
Dominance & $1.82(1.03)$ & $2.38(1.37)$ & $2.17(1.24)$ & $2.46(1.32)$ & $8.01 * * *$ & $2,4>1$ \\
\hline
\end{tabular}

Note. ${ }^{*} p<.05,{ }^{* *} p<.01,{ }^{* * * *} p<.001$

\subsection{Controlled Education Level, Family Income and Proximity}

To test mother-/daughter-in-law relationships with controlled factors of daughter-in-law educational level, family income and proximity, a multivariate analysis of variance (MANOVA) was conducted. Table 4 contains the adjusted means, standard deviations and $\mathrm{F}$ values. The results indicated that, when excluding educational level of the daughter-in-law, family income and proximity valuables, ethnicity of the daughters-in-law still made a significant difference in support, companionship and dominance relationships.

Table 4. Means, standard deviations and $\mathrm{F}$ value between Taiwanese and Vietnamese daughters-in-law in the mother-/daughter-in-law relationship with controlled factors of daughter-in-law educational level, family income, and proximity

\begin{tabular}{llll}
\hline & Taiwanese daughters-in-law M (SD) & Vietnamese daughters-in-law M (SD) & F-value \\
\hline Support & $3.05(.07)$ & $3.51(.10)$ & $15.87^{* * *}$ \\
Companionship & $3.26(.07)$ & $3.53(.09)$ & $10.27^{* *}$ \\
Conflict & $2.68(.06)$ & $2.44(.09)$ & 3.31 \\
Dominance & $2.21(.07)$ & $2.47(.10)$ & $3.98^{*}$ \\
\hline
\end{tabular}

Note. ${ }^{*} p<.05,{ }^{* *} p<.01,{ }^{* * * *} p<.001$

\section{Discussion}

The main purpose of this study is to compare the mother-/daughter-in-law relationships between Taiwanese-Vietnamese mothers-/daughters-in-law and Taiwanese-Taiwanese mothers-/daughters-in-law. The results indicated that, when compared with their Taiwanese counterparts, Vietnamese daughters-in-law felt they had a significantly more positive relationship, through the support and companionship, with their mothers-in-law. The findings may be explained with a study by Wang (2007), which interviewed 11 Vietnamese daughters-in-law and 6 Taiwanese mothers-in-law, and found their in-law relationships were harmonious. The Vietnamese daughters-in-law expressed their deepest gratitude towards their mothers-in-law, because they were unfamiliar with Taiwanese culture and the mothers-in-law were willing to teach them, help them do housework as well as care for them. They even felt that the mothers-in-law liked them more than they did their Taiwanese daughters-in-law. Taiwanese mothers-in-law also praised and were happy with their Vietnamese daughters-in-law, because the Vietnamese daughters-in-law did the housework diligently, submitted to instructions, did a good job at playing the role of daughter-in-law, and helped continue the husband's family line. By contrast, Taiwanese daughters-in-law have more complaints about intervention by their mothers-in-law in the areas of childrearing and privacy (Kung, 1999).

The results also revealed that it was the Vietnamese daughters-in-law, more so than the Taiwanese daughters-in-law, who felt that the mother-in-law had a more dominant role. Although previous researchers considered that the financial status of the couple and the educational level of the woman could change the ranking position in the authority structure of the family (Willams, Mehta, \& Lin, 1999; Chen, 2006), this study found that when controlling factors such as the educational level of the daughter-in-law and the family income of the couple, the ethnicity of the daughter-in-law was still an important factor in deciding the dominant role of the mother-in-law. In other words, for families with Vietnamese daughters-in-law, the position of the mother-in-law 
is supreme, and she can dominate over, demand, force, and even scold the daughter-in-law.

Significant difference in the mother-/daughter-in-law relationship due to educational level was seen only between daughters-in-law with middle school diploma or less and those with high school diploma degree or higher. However, $81 \%$ of daughters-in-law with middle school diploma or less were Vietnamese, since high school diploma has become the baseline for Taiwanese people. According to Chen's (2006) study, Taiwanese women with high school diploma or less had a more harmonious mother-/daughter-in-law relationship than those with college degrees or higher. Chen (2006) suggests that the more one associates with traditional Chinese female gender role norms such as obedience to authority, filial piety and respect of ancestors, the more harmonious their mother-/daughter-in-law relationship will be. Women with college degrees or higher have lower levels of association with these norms and higher frequency of conflict with the mother-in-law. However, data from this study did not support this contention. There were no significant differences in the mother-/daughter-in-law relationships among women with high school, college, university or higher degrees.

Family economic issues have been viewed as triggers that lead to conflict with the mother-in-law, especially in families with Vietnamese daughters-in-law. This study found that family income did not touch off conflict, but instead, emphasized the dominance of mother-in-law. In families with income less than NTD 30,000, the daughters-in-law felt more dominance from the mother-in-law. Even though previous research suggested that employment status could determine authority within a family ( $\mathrm{Su}, 2007)$, this study showed no difference between employed and unemployed.

The relationship between the mothers-in-law and daughters-in-law are related to proximity. The women who lived with their mothers-in-law felt more support and companionship but also suffered more conflict and domination. In this study, $41.8 \%$ of Taiwanese women and $54.5 \%$ of Vietnamese women lived with their mother-in-laws. It indicated that, in Taiwan, extended families are very common. Clearly, close proximity is a fact of life for many of these women. In western society, young couples are encouraged to live distanced to their in-laws to develop their own autonomy (Duvall, 1954). However, in Taiwanese society, young couples need to consider how to maintain a good in-law relationship since they must live near the older generation.

It was originally anticipated that Vietnamese daughters-in-law and Taiwanese mothers-in-law would have more conflicts due to difference in culture and habits. However, there were no such findings in this study. As Wang (2007) stated, this may be because they work harmoniously together, but there is unnoticeable tension building in the relationship. This study also found there are fewer conflicting relationships in families with Taiwanese daughters-in-law. We presume that the conflict items, measured by the frequency of quarrel occurrence, getting into a fight, and arguing with each other, happened less in Taiwanese families. In Taiwanese families, both sides avoid direct explicit conflict and dispute to maintain a superficial harmony, even if they are unwilling and reluctant. Hsu and Huang (2006) refer to this kind of conflict as "quiescent conflict". For future studies, the quiescent conflict items should be considered and included in the questionnaire items when designing measurement scales.

When factors such as educational level, family income and proximity were controlled, there was still significant difference in the ethnicity factor. Hence, there are still many unseen cultural factors that need further investigation and verification. This study has provided some baseline information for further studies. However, there are many unanswered questions for the further research. For example, why do the Vietnamese daughters-in-law have better relationships with their mothers-in-law than the Taiwanese daughters-in-law do; and what other factors are related to the relationships between the two generations.

\section{References}

Chen, H. (2006) Effects of harmonious relationship between mother and daughter-in-law, China. Journal of Home Economics, 39/40, 149-164.

Duvall, E. (1954). In-laws: Pro and con. New York, NY: Associated Press.

Hsu, M., \& Cheng, Y. (2006). Conflicts between career women and their mothers-in-law: An example of married nursing staff. New Taipei Journal of Nursing, 8(1), 45-56.

Hsu, S., \& Huang, L. (2006). Beyond mother-daughter affection: Multiple harmonies for mothers-and daughters-in-law. Indigenous Psychological Research, 26, 35-72.

Kung, H. (1999). Intergenerational Interaction between mothers-and Daughters-in-law: A Qualitative Study. Research in Applied Psychology, 4, 57-96.

Marotz-Baden, R., \& Cowan, D. (2009). Mothers-in-law and Daughters-in-law: The effects of proximity on 
conflict and stress. Family Relations, 36(4), 385-390. http://dx.doi.org/10.2307/584488

Ministry of the Interior. (2011, November 24). Population of Foreign Spouses and Spouses from Mainland China. Retrieved from http://www.immigration.gov.tw/ct.asp?xItem=1108546\&ctNode=29699\&mp=1

Shen, X. (2003). Stairway to heaven? Power and resistance within the commodified Taiwanese-Vietnamese Marriages. Unpublished master thesis. Institute of Sociology. National Tsing-Hua University, Taiwan.

$\mathrm{Su}, \mathrm{F}$. (2007). Same mothers-in-law Different daughters-in-law-research on interaction between Taiwanese mother-in-law and foreign daughter-in-law. Unpublished master thesis. Department of social science education. National Tai-Nan University, Taiwan.

Tsai, C., \& Chen, J. (2004). The positive perception of mothers in dual-earner families towards their mother-in-laws involving co-rearing young children. Journal of Taiwan Home Economics, 35, 66-74.

Wang, P. (2007). A Study of Interaction between Vietnamese Daughters-in-law and their Mothers-in-law. Unpublished master thesis. Department of Social Psychology, College of the Humanities and Social Science, Shih HsinUniversity, Taiwan.

Wang, U. (2005). An Analysis on Poverty of Families with Foreign/Chinese Spouses in Taiwan. Taiwan Social Work, 4, 1-32.

Willams, L., Mehta, K., \& Lin, H. (1999). Intergenerational influence in Singapore and Taiwan: The role of the elderly in family decisions. Journal of Cross-Cultural Gerontology, 14, 291-322. http://dx.doi.org/10.10 23/A:1006630800469

\section{Copyrights}

Copyright for this article is retained by the author(s), with first publication rights granted to the journal.

This is an open-access article distributed under the terms and conditions of the Creative Commons Attribution license (http://creativecommons.org/licenses/by/3.0/). 